Pesq. Vet. Bras. 35(6):541-546, junho 2015 DOI: $10.1590 / \mathrm{S} 0100-736 \mathrm{X} 2015000600009$

\title{
Neoplasmas em suínos: 37 casos $^{1}$
}

\author{
Juliana S. Brum², Tessie B. Martins ${ }^{3}$, Andréia Vielmo ${ }^{4}$, Marcia E. Hammerschmitt ${ }^{4}$, \\ Rafaela Talini ${ }^{5}$, Carolina D. Minozzo ${ }^{5}$ e Claudio S.L. Barros ${ }^{6 *}$
}

\begin{abstract}
Brum J.S., Martins T.B., Vielmo A., Hammerschmitt M.E., Talini R., Minozzo C.D. \& Barros C.S.L. 2015. [Neoplasia in swine: 37 cases.] Neoplasmas em suínos: 37 casos. Pesquisa Veterinária Brasileira 35(6):541-546. Programa de Pós-Graduação em Medicina Veterinária, Universidade Federal de Santa Maria, Camobi, Santa Maria, RS 97105-900, Brazil. E-mail: claudioslbarros@uol.com.br

Neoplasms in swine are rare. This paper describes neoplasms found in swine in the diagnostic routine of a veterinary pathology laboratory in the Central Region of Rio Grande do Sul, Brazil during a 49-year period, during which 2,266 cases of the various affections in swine were diagnosed. Of those 37 cases (1.6\%) were neoplasms. In decreasing order of prevalence, the following neoplasms were found: lymphoma (11 out of 37 cases), nephroblastoma (11/37), melanoma (8/37), and papilloma (2/37). Adenoma hepatocelular, carcinoma hepatocelular, cholangiocarcinoma, malignant fibrous histiocytoma, granulocytic sarcoma were each found in one case out of the 37 cases. The gross and histological aspects of these tumors are described and their epidemiology is compared with the data available in the literature for neoplasia in swine.
\end{abstract}

INDEX TERMS: Diseases of swine, neoplasms, lymphoma, nephroblastoma, melanoma, papilloma, hepatic tumors, malignant fibrous histiocytoma, granulocytic sarcoma.

RESUMO.- Neoplasmas em suínos são raros. Esse trabalho descreve os neoplasmas encontrados em suínos na rotina diagnóstica de um laboratório de patologia veterinária localizado na Região Central do Rio Grande do Sul. Durante um período de 49 anos, 2.266 casos de várias afecções em suínos foram encontrados, dos quais $37(1,6 \%)$ eram neoplasmas. Em ordem decrescente de frequência, os seguintes neoplasmas foram encontrados: Linfoma (11/37), nefroblastoma (11/37), melanoma (8/37) e papiloma (2/37). Adicional-

\footnotetext{
${ }^{1}$ Recebido em 30 de maio de 2015.

Aceito para publicação em 18 de junho de 2015.

Parte da tese de Doutorado do primeiro autor.

${ }^{2}$ Departamento de Medicina Veterinária (DMV), Setor de Ciências Agrárias (SCA), Universidade Federal do Paraná (UFPR), Rua dos Funcionários 1540, Juvevê, Curitiba, PR 80035-050, Brasil.

${ }^{3}$ Faculdade de Medicina Veterinária, Universidade Federal de Mato Grosso do Sul, Av. Senador Filinto Müller 2443, Campo Grande, MS 79074460, Brasil.

${ }^{4}$ Bolsista PIBIC, Laboratório de Patologia Veterinária, UFSM, Santa Maria, RS 97105-900.

${ }^{5}$ Graduação em Medicina Veterinária, DMV,SCA-UFPR, Curitiba, PR 80035-050.

${ }^{6}$ Programa de Pós-Graduação em Medicina Veterinária, área de concentração em Patologia Veterinária (PPGMV), Centro de Ciências Rurais (CCR), Universidade Federal de Santa Maria (UFSM), Av. Roraima 1000, Camobi, Santa Maria, RS 97105-900, Brasil. *Autor para correspondência: claudioslbarros@uol.com.br
}

mente, um caso de cada um dos seguintes tumores foi observado: Adenoma hepatocelular, carcinoma hepatocelular, colangiocarcinoma, histiocitoma fibroso maligno e sarcoma granulocítico. $\mathrm{O}$ aspecto macroscópico e histológico desses tumores é descrito e a sua epidemiologia é comparada com os dados disponíveis na literatura para neoplasia suína.

TERMOS DE INDEXAÇÃO: Doenças de suínos, neoplasmas, linfoma, nefroblastoma, melanoma, papiloma, tumores hepáticos, histiocitoma fibroso maligno, sarcoma granulocítico.

\section{INTRODUÇÃO}

Neoplasmas em suínos são raros. Isso ocorre por se tratar de uma espécie quase que unicamente de exploração econômica em que a grande maioria da população é abatida antes de atingir a "idade de câncer" (Sobestiansky et al. 1999, Stalder et al. 2012). Nos suínos a maioria dos neoplasmas observados são os que afetam animais jovens, incluindo linfoma (Rocha et al. 2011, Ogihara et al. 2012, Nishijo et al. 2013), nefroblastoma e melanoma (Okomo-Adhiambo et al. 2012). Estes tumores geralmente não causam sinais clínicos e na maioria das vezes são diagnosticados no abate, como lesões incidentais (Morés \& Driemeier 2012).

Nos últimos dez anos, entretanto, a prevalência de neoplasmas em suínos, principalmente naqueles criados como 
animais de companhia, aumentou consideravelmente (Newman \& Rohrbach 2012) e apareceram vários relatos de tumores antes considerados raros para a espécie: glanglioneuroma no intestino delgado (Murakami et al. 2011), carcinoma hepatocelular (Haddad \& Habecker 2012), feocromocitoma maligno (Martínez et al. 2011b), mastocitoma cutâneo, leiomioma/leiomiossarcoma, carcinoma de células escamosas e plasmocitoma (Newman \& Rohrbach 2012).

Trabalhos compilando as principais particularidades dos neoplasmas em suínos em uma determinada região são raros. Em razão disso, torna-se oportuno reunir as características dos neoplasmas diagnosticados na Região Central do Rio Grande do Sul, área de abrangência do Laboratório de Patologia Veterinária da Universidade Federal de Santa Maria (LPV-UFSM), objetivando contribuir com médicos veterinários, patologistas e responsáveis pela inspeção em abatedouros para o diagnóstico de tais lesões.

\section{MATERIAL E MÉTODOS}

Foram revisados todos os protocolos de exames histopatológicos e de necropsia relativos à espécie suína realizados no LPV-UFSM entre janeiro de 1964 e dezembro de 2012, na busca de casos de neoplasmas em suínos. Os protocolos referentes a esses casos foram separados e avaliados, e deles foram obtidas informações quanto à idade, ao sexo, à raça, à história clínica, à localização dos tumores, às descrições macroscópicas, às descrições microscópicas e ao diagnóstico morfológico. Foram considerados os diagnósticos morfológicos que constavam nos protocolos. Os suínos foram divididos em machos e fêmeas, independentemente de serem castrados ou não e categorizados como suínos de maternidade, suínos de creche, recria e terminação (idade de abate) e suínos adultos (incluindo matrizes e cachaços - animais de reprodução). Os neoplasmas tiveram sua prevalência calculada e suas principais características, determinadas.

\section{RESULTADOS E DISCUSSÃO}

Abrangendo os 49 anos do levantamento, um total de 2.266 $(4,9 \%)$ de todos os de protocolos examinados eram referentes a suínos (Sus scrofa domesticus), dos quais 37 (1,6\%) correspondiam a neoplasmas em suínos de produção. A população de suínos estudada reflete somente animais destinados à produção de carne e seus derivados, visto que não há relatos de suínos criados como animal estimação na região deste estudo. Atualmente, a grande maioria dos trabalhos descritos para tumores nesta espécie são referentes a suínos criados como animal de estimação, principalmente os Vietnamese pot-bellied pigs (Sus scrofa) (Munday \& Stedman 2002, Haddad \& Habecker 2012, Hirata et al. 2014). Esta raça não é encontrada no Brasil, onde a criação de suínos como animais pet é extremamente recente. 0 Quadro 1 mostra os neoplasmas observados no período do estudo e suas prevalências.

\section{Linfoma}

Linfoma foi observado em 11 casos (29,7\%). Dados de pesquisas realizadas em abatedouros de suínos em vários países (Misdorp 2003, Ogihara et al. 2012) indicam que o linfoma é o neoplasma mais frequente nessa espécie. $\mathrm{Na}$ França, a taxa desse neoplasma tem sido estimada em 6,5 casos por 100.000 abates, chegando a aproximadamente
Quadro 1. Prevalência dos neoplasmas de suínos diagnosticados no LPV-UFSM ${ }^{\text {a }}$ entre janeiro de 1964 e dezembro de 2012

\begin{tabular}{lcc}
\hline Neoplasma & $\mathrm{N}^{\mathrm{b}}$ & $\%$ \\
\hline Linfoma & 11 & 29,7 \\
Nefroblastoma & 11 & 29,7 \\
Melanoma & 8 & 21,7 \\
Papiloma & 2 & 5,4 \\
Adenoma hepatocelular & 1 & 2,7 \\
Carcinoma hepatocelular & 1 & 2,7 \\
Colangiocarcinoma & 1 & 2,7 \\
Histiocitoma fibroso maligno & 1 & 2,7 \\
Sarcoma granulocítico & 1 & 2,7 \\
Total & 37 & 100
\end{tabular}

${ }^{a}$ Laboratório de Patologia Veterinária da Universidade Federal de Santa Maria, ${ }^{\mathrm{b}}$ Número de casos.

$41 \%$ de todas as condenações relacionadas a neoplasmas (Jacobs et al. 2002).

Linfomas são relatados principalmente em suínos com menos de um ano de idade (Jacobs et al. 2002, Ogihara et al. 2012) e os achados observados neste estudo confirmam esse fato: oito suínos $(72,7 \%)$ foram considerados jovens (em torno de seis meses de idade - animais de terminação) e apenas dois suínos foram considerados adultos (animais de reprodução). Neoplasmas originários do sistema hematopoiético, como o linfoma, são os mais prevalentes entre animais jovens, especialmente em cães (Fighera et al. 2002). Em suínos, acredita-se que estejam relacionados a uma herança autossômica recessiva (Jacobs et al. 2002). Em um dos suínos não havia menção de idade no protocolo.

Com relação à raça, quatro $(36,3 \%)$ eram Landrace; cinco $(45,5 \%)$ não apresentavam raça definida; e em dois casos não havia menção do dado nos protocolos. A literatura não relata predisposição racial (Jacobs et al. 2002). Com relação ao sexo, cinco eram fêmeas $(45,5 \%)$; e dois eram machos $(18,2 \%)$, o que está de acordo com outros estudos, que relatam fêmeas duas vezes mais afetadas do que machos (Jacobs et al. 2002, Ogihara et al. 2012). Em quatro protocolos $(36,3 \%)$ não havia menção do sexo. Apesar do linfoma ser considerado um achado incidental de abatedouro, há relatos desse neoplasma como causa de morte em suínos (Rocha et al. 2011). Em dois suínos deste estudo $(18,2 \%)$, a morte resultou da acentuada invasão tecidual pelo linfoma, que num dos casos acometeu a medula óssea (linfoma leucêmico).

As lesões descritas nos protocolos caracterizavam-se pelo aumento dos linfonodos das carcaças (linfadenomegalia) e/ou por nodulações distribuídas aleatoriamente pelo parênquima de diversos órgãos. A distribuição anatômica dos casos de linfoma está representada no Quadro 2. Segundo dados da literatura, a forma clínica caracterizada por linfadenomegalia generalizada é menos comum que a forma multicêntrica, que cursa com envolvimento de outros órgãos (Jacobs et al. 2002). Nos casos por nós estudados a maioria dos linfomas apresentava tanto envolvimento dos linfonodos, como de diversas vísceras. 0 rim foi o órgão mais comumente afetado $(7 / 11)$, seguido dos linfonodos (6/11) e do fígado (4/11). A literatura cita o baço e a medula óssea como órgãos comumente acometidos por 
Quadro 2. Distribuição anatômica de 11 casos de linfoma em suínos diagnosticados no LPV-UFSM ${ }^{\text {a }}$ entre janeiro de 1964 e dezembro de 2012

\begin{tabular}{|c|c|c|c|c|c|c|c|c|c|c|c|}
\hline \multirow[t]{2}{*}{ Órgão } & \multicolumn{10}{|c|}{ Caso } & \multirow[b]{2}{*}{11} \\
\hline & 1 & 2 & 3 & 4 & 5 & 6 & 7 & 8 & 9 & 10 & \\
\hline Linfonodos & $x^{c}$ & $\mathrm{X}^{\mathrm{d}}$ & $x^{c}$ & $x^{c}$ & $\mathrm{x}^{\mathrm{c}}$ & & $\mathrm{x}^{\mathrm{e}}$ & & & & \\
\hline Vísceras ${ }^{\mathrm{b}}$ & & & & & $\mathrm{x}$ & & $\mathrm{x}$ & & & & \\
\hline Rim & $\mathrm{x}$ & & $\mathrm{x}$ & $\mathrm{x}$ & & $\mathrm{x}$ & & $\mathrm{x}$ & & $\mathrm{x}$ & $\mathrm{x}$ \\
\hline Fígado & $\mathrm{x}$ & & & $\mathrm{x}$ & & & & & $\mathrm{x}$ & & $\mathrm{x}$ \\
\hline Baço & & & & $\mathrm{x}$ & & & & $\mathrm{x}$ & & & \\
\hline Coração & & & & & & & & $\mathrm{x}$ & & & \\
\hline Ovário & $\mathrm{x}$ & & & & & & & & & & \\
\hline Estômago & & & & & & & & $\mathrm{x}$ & & & \\
\hline Medula óssea & & & & & & & & $\mathrm{x}$ & & & \\
\hline Intestino grosso & & & & & & & & & & & $\mathrm{x}$ \\
\hline Seio nasal & & & & & & & & & & & $\mathrm{x}$ \\
\hline $\begin{array}{l}\text { a Laboratório de } \\
\text { Maria, b Segund } \\
\text { ceras, com exc } \\
\text { linfonodos, }{ }^{\mathrm{d}} \mathrm{Er} \\
\text { torácicos, }{ }^{\mathrm{e}} \mathrm{Com}\end{array}$ & óri & clí & & & $\begin{array}{l}\text { Jniv } \\
\text { enve } \\
\text { ivolv } \\
\text { os p }\end{array}$ & & act & & & $\begin{array}{l}\text { de S } \\
\text { s as } \\
\text { ado } \\
\text { rena } \\
\text { ça. }\end{array}$ & $\begin{array}{l}\text { vinta } \\
\text { vís- } \\
\text { dos } \\
\text { is e }\end{array}$ \\
\hline
\end{tabular}

linfoma (Jacobs et al. 2002, Ogihara et al. 2012). Neste estudo um suíno apresentou envolvimento da medula óssea, ao que foi atribuída a morte do animal, conforme descrito anteriormente.

Neste estudo encontrou-se ainda a descrição de uma massa nos seios nasais; linfoma nesse sítio anatômico já havia sido relatado anteriormente em um suíno selvagem (Rocha et al. 2011). Linfomas na cavidade nasal são considerados relativamente comuns em gatos (Mukaratirwa et al. 2001) e raros para outras espécies (Terada 2011). Na literatura há descrições do acometimento desse sítio anatômico no homem (Terada 2011), em equinos (Gerard et al. 2010), bovinos (Crocker \& Rings 1998) e cães (Kaldrymidou et al. 2000).

Nos linfonodos, macroscopicamente se observava substituição do parênquima nodal por massa homogênea, firme e branca; nos demais órgãos, os nódulos apresentavam tamanhos variados, entre 0,5 e 4,0 cm de diâmetro, de mesma cor, padrão e consistência, semelhante ao descrito para outras espécies (Fighera et al. 2002, Fry \& McGavin 2007). Microscopicamente, na coloração de rotina, eram caracterizados por proliferação de células redondas com limites citoplasmáticos distintos e citoplasma escasso e núcleo central e redondo, formado por cromatina agregada. 0 pleomorfismo foi leve em todos os casos e figuras de mitose não foram observadas.

\section{Nefroblastoma}

Nefroblastoma foi observado igualmente em 11 casos $(29,7 \%)$. Também chamado de nefroma embrionário, trata-se de um tumor congênito, originário de uma transformação neoplásica durante a nefrogênese (Meuten 2002, Misdorp 2003). É um neoplasma comum no suíno e reconhecido como o principal tumor primário renal da espécie, embora sua prevalência possa variar dependendo da região (Misdorp 2003, Grieco et al. 2006). Nos EUA a incidência estimada é de 20 nefroblastomas por 100.000 suínos; porém na Rússia é somente 0,35 tumores a cada 100.000 suínos (Grieco et al. 2006).
Por ser o nefroblastoma um neoplasma congênito, é observado em suínos jovens (Meuten 2002), e os resultados deste estudo tendem a confirmar essa observação: em dez dos 11 casos observados, o neoplasma foi observado no matadouro e os suínos tinham 5-10 meses de idade. Em um caso o neoplasma foi incriminado como a causa da morte do suíno, pois metástases eram observadas nos linfonodos, no pulmão, na parede torácica interna, no fígado e no útero. Apesar de na maioria dos casos ser considerado como um achado incidental de abatedouro, como os casos relatados, ocasionalmente os nefroblastomas podem adquirir grandes proporções, comprimindo órgãos da cavidade abdominal, e/ou adquirir componentes malignos, semelhante aos nefroblastomas em crianças, e metastatizar, principalmente para os linfonodos renais (Misdorp 2003, Grieco et al. 2006).

Parece não haver diferença entre a proporção de machos e fêmeas afetados (Meuten 2002). Neste estudo, apenas em quatro casos o sexo estava mencionado nos protocolos, sendo dois machos e duas fêmeas. A raça estava mencionada em seis protocolos, sendo quatro suínos sem raça definida, dois Duroc e um Landrace.

Em seis dos 11 casos, as lesões macroscópicas caracterizavam-se por uma única massa, de 2,5-14 cm em seu maior eixo, localizada sobre a superfície renal (Fig.1). Ao corte, as massas eram multilobuladas ou exibiam pequenas formações císticas. Em três casos os rins exibiam nódulos difusos, com até $3 \mathrm{~cm}$ de diâmetro que por vezes invadiam a zona cortical. Em dois casos os dados macroscópicos não constavam nos protocolos. Todas as lesões apresentavam superfície natural levemente irregular e brancacenta e, ao corte, eram firmes e homogeneamente branco-amareladas. As principais características macroscópicas descritas para o nefroblastoma são semelhantes às descritas na literatura (Meuten 2002, Misdorp 2003). Os mesmos autores citam ainda que, ocasionalmente, as massas podem ser difusas e em ambos os rins.

Microscopicamente, o nefroblastoma caracteriza-se por proliferação de células embrionárias em diferentes estágios de diferenciação, por vezes formando estruturas semelhantes a túbulos, de diâmetros diferenciados. Em

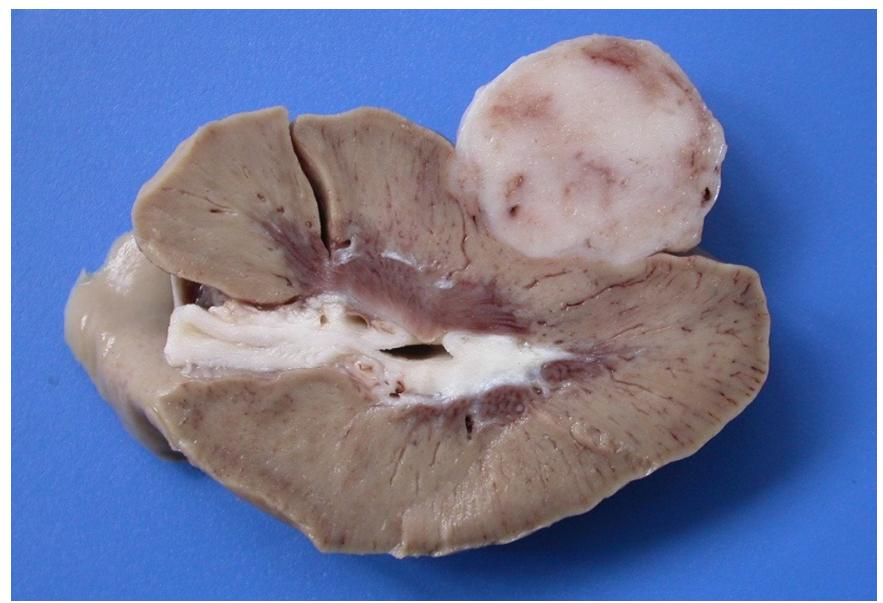

Fig.1. Neoplasmas em suínos. Nefroblastoma. Observa-se massa brancacenta comprimindo o córtex renal. 
alguns casos havia descrição de estruturas arredondadas formadas a partir de invaginações do epitélio para a luz tubular. Essas estruturas foram interpretadas como tufos glomerulares primitivos, que é um aspecto característico do nefroblastoma (Hayashi et al. 1986).

\section{Melanoma}

Melanoma foi observado em oito casos $(21,7 \%)$ e constituiu o principal tumor cutâneo nos suínos deste estudo. Apesar de alguns autores relatarem uma baixa prevalência deste neoplasma (Misdorp 2003, Martínez et al. 2011a), suínos Duroc, Vietnamese pot-bellied pigs e algumas raças miniaturas são reconhecidas como predispostas geneticamente para o desenvolvimento de melanomas congênitos, apresentando incidência aumentada (Pérez et al. 2002, Misdorp 2003, Okomo-Adhiambo 2012). Sua forma benigna (melanocitoma) também é comumente descrita em suínos (Goldschmidt \& Hendrick 2002, Pérez et al. 2002). Dos oito suínos com melanoma neste estudo, três eram Duroc, três não tinham raça definida, e em um caso não havia menção de raça, isto é, uma proporção semelhante à descrita maioria dos relatos (Goldschmidt \& Hendrick 2002, Okomo-Adhiambo 2012). No entanto, um dos suínos era cruzamento de Landrace com Large White e, neste caso, de pele despigmentada, situação em que o neoplasma é considerado raro (Misdorp 2003).

A idade estava descrita em sete protocolos. Cinco suínos pertenciam à categoria de creche e terminação (38 dias a seis meses) e dois eram adultos, com um a três anos de idade. Vários estudos corroboram esses achados quando esclarecem que os melanomas são congênitos ou que surgem nas primeiras semanas de vida do suíno (Pérez et al. 2002, Misdorp 2003). Nos suínos adultos não constava nos protocolos o tempo de evolução da lesão. Aproximadamente $85-90 \%$ desses neoplasmas regridem espontaneamente, sem recidivas, através de uma resposta imune mediada por células (Goldschmidt \& Hendrick 2002, Pérez et al. 2002), porém alguns animais podem acabar morrendo devido ao avanço da doença (Okomo-Adhiambo 2012). No grupo de oito suínos afetados pelo melanoma, quatro eram machos e um era fêmea; nos outros três casos o sexo não constava do protocolo. A literatura não menciona qualquer predisposição relativa ao gênero.

As lesões de melanoma foram observadas na pele em sete casos e no linfonodo, em um caso, em que o tumor foi interpretado como uma metástase. Metástases de melanomas são bem descritas, principalmente quando os animais sobrevivem por um tempo maior (Goldschmidt \& Hendrick 2002). Acredita-se que neste caso o tumor primário, com origem provavelmente na pele, metastatizou e regrediu, não podendo ser observado no local primário no momento da inspeção. Em apenas três casos o suíno afetado havia sido abatido para consumo; nos outros cinco casos o diagnóstico foi realizado por biópsia incisional ou necropsia. Acredita-se que este fato ocorra por que lesões de pele chamam muito a atenção dos proprietários e causam má impressão, fazendo com que seja procurada orientação veterinária. Três suínos apresentavam lesão cutânea na região torácica dorsal; dois apresentavam le- são nos membros posteriores; em um suíno a lesão estava localizada na região abdominal; e em outro a lesão localizava-se na base da orelha. Lesões localizadas no flanco são relatadas como comuns (Goldschmidt \& Hendrick 2002), porém o principal sítio observado neste estudo foi o tórax dorsal (Fig.2).

Macro e microscopicamente, as lesões eram semelhantes às descritas na literatura (Goldschmidt \& Hendrick 2002, Misdorp 2003, Okomo-Adhiambo 2012). Caracterizavam-se por massa solitária, de 1-8 cm de diâmetro. Somente um dos suínos apresentava dois focos do tumor. Nos protocolos revisados há referências a "crescimento acentuado"; a superfície natural dos neoplasmas era irregular, na maioria das vezes ulcerada e difusamente escura. Ao corte, os tumores eram macios e homogeneamente pretos. Microscopicamente, os melanomas foram caracterizados por proliferação dérmica de células neoplásicas formando um denso manto em meio a um estroma escasso que, na maioria das vezes invadia a epiderme, ulcerando-a. A maior parte das células exibia grande quantidade de melanina no citoplasma. Baixa quantidade de mitoses foram descritas na maioria dos casos e o pleomorfismo celular variou de leve a moderado.

\section{Papiloma}

O papiloma foi observado na pele de dois dos 37 suínos $(5,4 \%)$. Em um dos casos lesões proliferativas idênticas na pele do corpo, interpretadas como papilomatose, foram observadas num macho reprodutor adulto jovem e em outros três animais da mesma propriedade. Geralmente casos semelhantes de papilomatose cutânea são congênitos e podem ou não estar associados com papilomavírus (Nishiyama et al. 2011). Não foram realizados testes específicos para detecção de antígeno viral.

O segundo caso é de um suíno adulto que apresentava lesões papilomatosas difusas na pele do escroto, uma alteração sem significado clínico que é comumente descrita para cachaços velhos (Rech et al. 2013). Em ambos os casos, as as lesões macroscópicas eram proliferativas, semelhantes a verrugas, com 1-1,5 cm de diâmetro. Basicamente, a lesão microscópica descrita para ambos os casos foi proli-

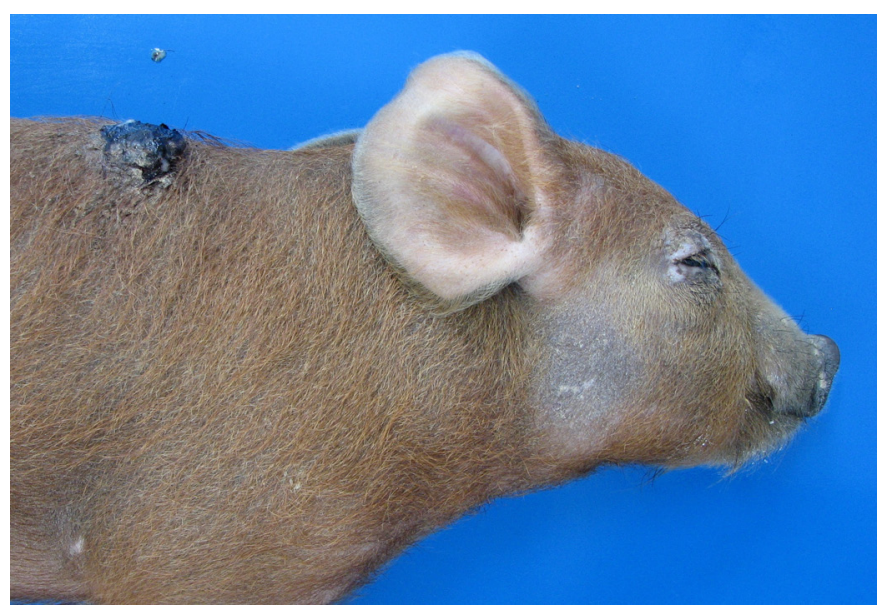

Fig.2. Neoplasmas em suínos. Melanoma. Observa-se massa enegrecida na região torácica dorsal de leitão jovem. 
feração de ceratinócitos epidérmicos, formando projeções exofíticas, recobertas por grande quantidade de ceratina. Essas formas de apresentação macro e microscópica são semelhantes às descritas em outros estudos (Vitovec et al. 1999, Goldschmidt \& Hendrick 2002).

\section{Neoplasmas primários do fígado}

Neoplasmas primários do fígado foram observados em três suínos (8,2\%): adenoma hepatocelular, carcinoma hepatocelular e colangiocarcinoma. Todos foram considerados achados incidentais de abatedouro, e em dois deles a idade tinha sido anotada: seis meses e dois anos.

No suíno de terminação (seis meses de idade) o tumor era benigno e originário dos hepatócitos (adenoma hepatocelular). Este neoplasma é raramente relatado em suínos (Ohfuji et al. 1992, Cullen \& Popp 2002). Alguns autores (Cullen \& Popp 2002) citavam que uma alteração comumente observada no fígado de suínos de abatedouro e que poderia ser interpretada com adenoma hepatocelular seria a hiperplasia nodular. Mais recentemente, porém, a hiperplasia nodular passou a ser considerada de ocorrência exclusiva em cães (Cullen 2007, Van Sprundel et al. 2013). A lesão macroscópica caracterizava-se por massa de superfície natural irregular, constituída por nódulos acinzentados ou vermelho-vinho e pequenas formações císticas, delimitadas por proliferação de tecido fibroso. Histologicamente, caracterizava-se por proliferação de hepatócitos, formando ilhas bem delimitadas e circunscritas por tecido conjuntivo abundante, que comprimia o parênquima adjacente. As ilhas de hepatócitos neoformados caracterizam-se pela ausência de organização lobular.

No caso do suíno adulto (dois anos de idade), o neoplasma era maligno e também se originava dos hepatócitos (carcinoma hepatocelular). Macroscopicamente, as lesões podiam ser observadas em todo o parênquima hepático e eram branco-amareladas ou avermelhadas. Apesar de haver descrição de tumores únicos, massas difusas pelo parênquima hepático predominam nas descrições do carcinoma hepatocelular em suínos (Haddad \& Habecker 2012, Newman \& Rohrbach 2012). Histologicamente a proliferação era semelhante à descrita para seu correspondente benigno, porém com pleomorfismo moderado a acentuado.

Colangiocarcinoma foi observado em um suíno macho, sem raça definida, adulto, e caracterizava-se por nódulos de 0,5-3 cm de diâmetro disseminados pelo parênquima hepático. Microscopicamente, o tumor era descrito como uma proliferação de células epiteliais neoplásicas que substituía o parênquima hepático adjacente. As células agrupavam-se em ninhos, semelhantes a estruturas glandulares, em meio a um escasso estroma colagenoso. As descrições macro e microscópicas são semelhantes ao que foi observado em outros relatos, onde as lesões também eram disseminadas no parênquima, porém esses animais apresentavam metástase para outros órgãos (Newman \& Rohrbach 2012).

Em outros estudos que descrevem estes neoplasmas, há diferenças significativas. Neoplasmas hepáticos são descritos em suínos criados como pets, que morreram em consequência da doença, com uma média de idade de 15,5 anos (Haddad \& Habecker 2012, Newman \& Rohrbach 2012).
Acredita-se que a questão da idade seja o principal ponto a ser considerado, pois os suínos apresentavam idade mais avançada e aparentemente a doença estava em estágio mais grave, o que pode ser comprovado pelas descrições de metástases e pelo fato de ter sido a causa da morte, o que não foi observado neste trabalho.

\section{Histiocitoma fibroso maligno}

Histiocitoma fibroso maligno foi observado em um caso. Este neoplasma é considerado pouco frequente, descrito em maior proporção em cães e gatos (Jacobs et al. 2002), no homem (Wang et al. 2014) e raramente em outras espécies como bovinos (Sartin et al. 1996) e suínos (Tanimoto et al. 1988). Neste estudo, o histiocitoma localizava-se baço de um suíno de terminação, sem raça definida, abatido para consumo e caracterizava-se por uma massa de aproximadamente $10 \mathrm{~cm}$ de diâmetro localizada em um dos polos do baço, semelhante a relato encontrado na literatura (Tanimoto et al. 1988). Histologicamente, o neoplasma foi descrito como uma proliferação de células fusiformes formando feixes em diversas direções. Em meio a essa proliferação havia células redondas, por vezes multinucleadas. 0 pleomorfismo era leve e o índice mitótico, baixo.

\section{Sarcoma granulocítico eosinofílico}

Sarcoma granulocítico foi observado, como um achado incidental, em uma porca com cinco anos de idade, sem raça definida, abatida para consumo. Macroscopicamente, caracterizava-se por massas esverdeadas no rim e ossos (costelas e vértebras). Microscopicamente o neoplasma era caracterizado por focos não delimitados de mielócitos, exibindo grânulos eosinofílicos no citoplasma e substituindo as estruturas adjacentes dos diferentes tecidos. Maiores detalhes deste caso já foram publicados (Brum et al. 2012). 0 mesmo neoplasma, com alguns aspectos semelhantes deste estudo, já havia sido relatado em outro suíno (Fisher \& Olander 1978).

\section{CONCLUSÕES}

Durante o período de abragência do estudo, os principais neoplasmas diagnosticados em suínos foram o linfoma e nefroblastoma.

Estes tumores foram observados predominantemente como achados incidentais de abatedouro, e acometeram principalmente o rim.

O melanoma cutâneo, que foi o terceiro tumor mais comumente observado, ocorreu principalmente na região torácica dorsal e foi predominantemente remetido como espécime de biópsia.

\section{REFERÊNCIAS}

Brum J.S., Lucena R.B., Martins T.B., Fighera R.A. \& Barros C.S.L. 2012. Eosinophilic granulocytic sarcoma in a pig. J. Vet. Diagn. Invest. 24:807-811.

Crocker C.B. \& Rings D.M. 1998. Lymphosarcoma of the frontal sinus and nasal passage in a cow. J. Am. Vet. Med. Assoc. 213:1472-1474. (Resumo)

Cullen J.M. \& Popp J.A. 2002. Tumors of the liver and gall bladder, p.483508. In: Meuten D.J. (Ed.), Tumors in Domestic Animals. 4th ed. Iowa State Press, Ames. 
Cullen J.M. 2007. Liver, biliary system and exocrine pancreas, p.393-461. In: McGavin M.D. \& Zachary J.F. (Eds), Pathologic Basis of Veterinary Disease. 4th ed. Mosby Elsevier, St Louis.

Fighera R.A., Souza T.M. \& Barros C.S.L. 2002. Linfossarcoma em cães. Ciência Rural 32:895-899.

Fisher L.F. \& Olander H.J. 1978. Spontaneous neoplasms of pigs: a study of 31 cases. J. Comp. Pathol. 88:505-517.

Fry M.M. \& McGavin M.D. 2007. Bone marrow, blood cells, and lymphatic system. In: McGavin M.D. \& Zachary J.F. (Eds), Pathologic Basis of Veterinary Disease. 4th ed. Mosby Elsevier, St Louis.

Gerard M., Pruitt A. \& Thrall D.E. 2010. Radiation therapy communication: nasal passage and paranasal sinus lymphoma in a pony. Vet. Radiol. Ultrasound 51:91-101.

Goldschmidt M.H. \& Hendrick M.J. 2002. Tumors of the skin and soft tissues, p.45-118. In: Meuten D.J. (Ed.), Tumors in Domestic Animals. 4th ed. Iowa State Press, Ames.

Grieco V., Riccardi E., Belotti S. \& Scanziani E. 2006. Immunohistochemical study of porcine nephoblastoma. J. Comp. Pathol. 134:143-151.

Haddad J.L. \& Habecker P.L. 2012. Hepatocellular carcinomas in Vietnamese pot-bellied pigs (Sus scrofa). J. Vet. Diagn. Invest. 24:1047-1051.

Hayashi M., Tsuda H., Okumura M., Hirose M. \& Ito N. 1986. Histopathological classification of nephoblastomas in slaughtered swine. J. Comp. Pathol. 96:35-46.

Hirata A., Miyazaki A., Sakai H., Imada N., Kitani R., Nikami H. \& Yanai T. 2014. Choriocarcinoma-like tumor in a potbellied pig (Sus scrofa). J. Vet. Diagn. Invest. 26:163-166.

Jacobs R.M., Messick J.B. \& Valli V.E. 2002.Tumors of the hemolymphatic system, p.119-198. In: Meuten D.J. (Ed.), Tumors in Domestic Animals. 4th ed. Iowa State Press, Ames.

Kaldrymidou E., Papaioannou N., Poutahidis T., Karayannopoulou M., Gruys E., Toliou T. \& Tsangaris T. 2000. Malignant lymphoma in nasal cavity and paranasal sinuses of a dog. J. Vet. Med. A 47:457-462. (Resumo)

Martínez J., Martínez V., Grau-Roma L., López J. \& Segalés J. 2011a. Multiple cutaneous mast cell tumors in a pig. J. Vet. Diagn. Invest. 23:1222-1225.

Martínez J., Galindo-Cardiel I., Díez-Padrisa M., López-Sabater E.I. \& Segalés J. 2011b. Malignant pheochromocytoma in a pig. J. Vet. Diagn. Invest. 24:207-210.

Meuten D.J. 2002. Tumors of the urinary system, p.509-546. In: Meuten D.J. (Ed.) Tumors in Domestic Animals. 4th ed. Iowa State Press, Ames.

Misdorp W. 2003. Congenital and hereditary tumours in domestic animals. 2. Pigs: a review. Vet. Quart. 25:17-30.

Morés N. \& Driemeier D. 2012. Neoplasias, p.787-792. In: Sobestiansky J. \& Barcellos D. (Eds), Doenças dos Suínos. 2ª̣ ed. Cânone Editorial, Goiânia.

Mukaratirwa S., Van der Linde-Sipman J.S. \& Gruys E. 2001. Feline nasal and paranasal sinus tumours: clinicopathological study, histomorphological description and diagnostic immunohistochemistry of 123 cases. J. Feline Med. Surg. 3:235-245.

Munday J.S. \& Stedman N.L. 2002. Uterine leiomyomas in two Vietnamese pot-bellied pigs (Sus scrofa). Vet. Pathol. 39:580-583.

Murakami M., Sakai H., Mizutani K. \& Yanai T. 2011. Ganglioneuroma in the small intestine of a juvenile pig. J. Vet. Sci. 73:1501-1504.
Newman S.J. \& Rohrbach B. 2012. Pot-bellied pig neoplasia: a retrospective case series (2004-2011). J. Vet. Diagn. Invest. 24:1008-1013.

Nishijo S., Ogihara K., Ishikawa Y. \& Kadota K. 2013. Signet ring cell lymphoma with plasmacytic differentiation in a pig. J. Vet. Sci. 75:799-802.

Nishiyama S., Akiba Y., Kobayashi Y., Shiga A., Kamiie J. \& Shirota K. 2011. Congenital cutaneous fibropapillomatosis with no evidence of papillomavirus infection in a piglet. J. Med. Sci. 73:283-285.

Ogihara K., Ohba T., Takai H., Ishikawa Y. \& Kadota K. 2012. Lymphoid neoplasms in swine. J. Vet. Sci. 74:149-154.

Ohfuji S., Kosuda M. \& Matsui T. 1992. Hepatocholangioadenoma in a pig. J. Comp. Pathol. 106:89-92.

Okomo-Adhiambo M., Rink A., Rauw W.M. \& Gomez-Raya L. 2012. Gene expression in Sinclair swine with malignant melanoma. Animal 6:179192.

Pérez J., Garcia P.M., Bautista M.J., Millán Y., Ordás J. \& De Las Mulas J.M. 2002. Immunohistochemical characterization of tumor cells and inflammatory infiltrate associated with cutaneous melanocytic tumors of Duroc and Iberian swine. Vet. Pathol. 39:445-451.

Rech R.R., Silva M.C., Langohr I.M., Marques M.G., Pescador C.A., Gustavo S.S., Dutra M.C., Brum J.S., Kramer B., Bordin L.C. \& Silva V.S. 2013. Nem tudo que parece ser, é lesão: aspectos anatômicos, não lesões, artefatos, lesões sem significado clínico e alterações post mortem encontrados na necropsia de suínos domésticos e selvagens (Sus scrofa). Pesq. Vet. Bras. 33:1237-1255.

Rocha P.R.D., Scaglione F.E., Ferroglio E., Chiappino L., Bollo E. \& Capucchio M.T. 2011. Diffuse multicentric large B-cell lymphoma invading the central nervous system in a European wild boar (Sus scrofa). J. Wildlife Dis. 47:1040-1042.

Sartin E.A., Hudson J.A., Herrera G.A., Dickson A.M. \& Wolfe D.F. 1996. Invasive malignant fibrous histiocytoma in a cow. J. Am. Vet. Med. Assoc. 208:1709-1710. (Resumo)

Sobestiansky J., Barcellos D., Morés N., Carvalho L.F., Oliveira S., Moreno A.M. \& Roehe P.M. 1999. Clínica e Patologia Suína. Art 3 Impressos, Goiânia, p.314-318.

Stalder K., D’Allaire S., Drolet R. \& Abell C. 2012. Longevity in breeding animals, p.50-59. In: Zimmerman J.J., Karriker L.A., Ramirez A., Schwaetz K.J. \& Stevenson G.W. (Eds), Diseases of Swine. 10th ed. Blackwell Publishing, Ames.

Tanimoto T., Ohtsuki Y., Sonobe H., Takahashi R. \& Nomura Y. 1988. Malignant fibrous histiocytoma in the spleen of a pig. Vet. Pathol. 25:330332.

Terada T. 2011. Primary diffuse large B-cell lymphoma of the ethmoid sinus. Int. J. Clin. Exp. Pathol. 4:799-801.

Van Sprundel R.G.H.M., Van den Ingh T.S.G.A.M., Guscetti F., Kershaw O., Kanemoto H., Van Gils H.M., Rothuizen J., Roskams T. \& Spee B. 2013. Classification of primary hepatic tumours in the dog. Vet. J. 197:596606.

Vítovec J., Kursa J., Kratochvíl P. \& Skálová A. 1999. Congenital fibropapillomatosis in a piglet. Vet. Pathol. 36:83-85.

Wang J., Zhong W., Xu Y., Feng L., Li Y. \& Dong B. 2014. A primary malignant fibrous histiocytoma of the scalp and intracranial tumor bleedind: a case report. Med. Case Rep. J. 8:50-54. 